\title{
Cutaneous T cell lymphoma and classic Hodgkin lymphoma of the B cell type within a single lymph node: composite lymphoma
}

\author{
M Steinhoff, M Hummel, C Assaf, I Anagnostopoulos, R Treudler, C C Geilen, H Stein, C E Orfanos
}

J Clin Pathol 2004;57:329-331. doi: 10.1136/icp.2003.011882

Composite lymphomas are defined as two unrelated, morphologically and genetically distinct lymphomas occurring at the same point in time within the same tissue or organ. Since their original definition, several composite lymphomas have been reported exclusively based on morphological grounds. However, with the application of immunhistological and molecular biological techniques it has become evident that many so called "composite" lymphomas do not fulfil the necessary criteria, because they merely represent two different morphological phenotypes of the same malignant clone. This report describes the manifestation of a true composite lymphoma within a single cervical lymph node, which is composed of a cutaneous $T$ cell lymphoma and a classic Hodgkin lymphoma of B cell type-a very rare finding indeed.

L ymphomas are malignant clonal proliferations of $\mathrm{T}$ cells, B cells, or rarely natural killer cells. Different types of -lymphomas occurring in the same patient have frequently been described in the literature. However, the histological manifestation of more than one malignant lymphoma simultaneously present within the same organ is a rare finding. In 1954, the term "composite lymphoma" was introduced to describe this category. ${ }^{1}$ This term was adopted by the working formulation, defining composite lymphomas as those with "two distinctly demarcated types of nonHodgkin lymphoma or the rare association of Hodgkin disease with a form of non-Hodgkin lymphoma within a single organ or tissue". With the advent of immunohistochemistry and modern molecular techniques, it was shown that two different morphological patterns or phenotypes do not always represent two clonally unrelated types of lymphoma..$^{2-4}$ In many of these cases, the so called composite lymphoma might result from either clonal transformation or development from a common precursor cell, and would therefore not be a true composite lymphoma, according to the original definition. ${ }^{56}$

"The histological manifestation of more than one malignant lymphoma simultaneously present within the same organ is a rare finding"

Composite lymphomas consisting of B and T cell lymphomas seem to be extremely rare. ${ }^{7}$ Here, we report a patient with the simultaneous appearance of a cutaneous $\mathrm{T}$ cell lymphoma (CTCL) and a classic Hodgkin lymphoma (cHL) within a single cervical lymph node. Because cHL can originate from both $\mathrm{B}$ and $\mathrm{T}$ cells, three scenarios appear to be possible (fig 1): (1) the CTCL and CHL are derived from the same $\mathrm{T}$ cell clone. (2) the CTCL and CHL originated from different $\mathrm{T}$ cell clones. and (3) cHL is of B cell origin and cannot be clonally related to CTCL.

To decide which of these possibilities is represented by our case, we analysed the immunophenotypical and the molecular features of both lymphomas.

\section{CASE REPORT}

An 81 year old woman presented with a solitary erythematous infiltrated plaque on her back in May 2000. A skin biopsy showed typical features of a small to medium sized pleomorphic CD4 positive CTCL. General examination showed no lymphadenopathy, but the spleen was easily palpable, a finding that had been known for three years. Clinical staging revealed no further cutaneous or systemic manifestation of CTCL. Treatment with local cream-PUVA led to the complete remission of the disease. Seven months later, the patient presented with an enlarged cervical lymph node, but with no further skin manifestation. Lymph node biopsy was performed and revealed infiltration by a medium sized $\mathrm{T}$ cell lymphoma and by cHL. The patient was fully staged again, and all investigations failed to reveal other sites of disease, except for the known splenomegaly. Two cycles of systemic chemotherapy in accordance with the ABVD protocol ( $2 / 3$ dose) were applied.

\section{RESULTS AND DISCUSSION}

Initial skin biopsy showed a small to medium sized pleomorphic CD4 positive CTCL. Morphological and immunohistological analysis of the cervical lymph node revealed an infiltration of a highly proliferating medium sized $\mathrm{T}$ cell population, leading to partial effacement of the normal lymph node architecture. The neoplastic $\mathrm{T}$ cells expressed CD2, CD3, CD4, partly CD30 (fig 2B,C), and showed a lack of expression of CD8, and part of the T cell receptor (TCR) $\beta$ chain; ALK protein expression was not detectable (table 1). Both T cell lesions were investigated further to look for clonal $\mathrm{T}$ cell populations by means of TCR- $\gamma$ polymerase chain reaction (PCR). GeneScan analysis of the resulting amplificates demonstrated dominant PCR products of the same size; furthermore, sequence analysis confirmed the presence of identical $\mathrm{T}$ cell clones in the lymph node and skin. ${ }^{89}$

In addition to the $\mathrm{T}$ cell lymphoma, atypical cells were present in the lymph node, which displayed the morphological features of Hodgkin and Reed-Sternberg (HRS) cells (fig $\mathrm{lA}-\mathrm{F}$ ). They were embedded in the remnants of $\mathrm{B}$ cell zones, surrounded by T cells, and expressed CD30 and CD15,

Abbreviations: $\mathrm{BSAP}, \mathrm{B}$ cell specific activator protein; $\mathrm{CHL}$, classic Hodgkin lymphoma; CTCL, cutaneous T cell lymphoma; EBV, EpsteinBarr virus; HRS, Hodgkin and Reed-Sternberg; PCR, polymerase chain reaction; TCR, T cell receptor 
।

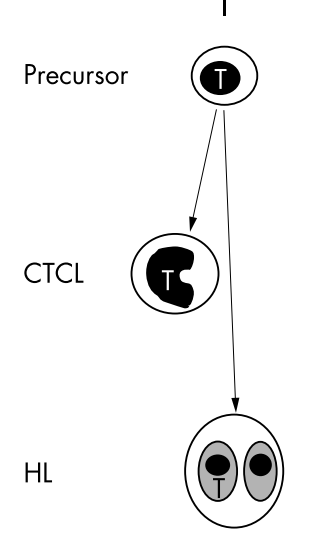

$\|$

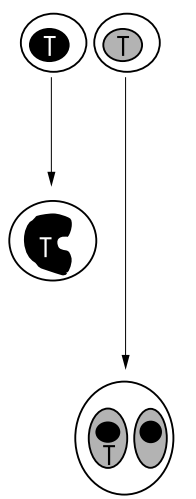

III

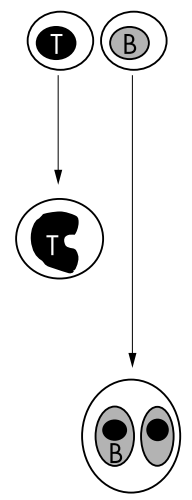

Figure 1 Scheme of three possible scenarios and histological staining of the lymph node. In scenario I, a cutaneous T cell lymphoma (CTCL) and a classic Hodgkin lymphoma $(\mathrm{cHL})$ originate from the same fumour cell precursor, thus merely reflecting two histological variants of the same tumour. In contrast, in scenarios II and III, CTCL and cHL are unrelated to each other and thus represent a true composite lymphoma. T, T cell; B, B cell.

Table 1 Immunophenotypical features of the composite lymphoma in a single lymph node

\begin{tabular}{lll}
\hline Antigen & CTCL & cHL \\
\hline CD20 & - & Single positive cells \\
BSAP & - & + \\
BOB.1 & - & - \\
OCT2 & - & $-/+$ \\
CD2 & + & - \\
CD3 & + & - \\
CD4 & + & - \\
CD8 & - & - \\
TCR- $\beta$ & $-/+$ & - \\
Perforin & - & - \\
TIA-1 & - & + \\
CD30 & $-/+$ & $-/+$ \\
CD15 & - & + \\
EBV-LMP-1 & - & - \\
EBNA2 & - & - \\
ALK-1 & - &
\end{tabular}

BSAP, B cell specific activator protein; cHL, classical Hodgkin lymphoma; CTCL, cutaneous T cell lymphoma; EBNA2, Epstein-Barr virus encoded nuclear antigen 2; EBV-LMP-1, Epstein-Barr virus latent membrane protein $1 ;$ TCR, T cell receptor; + , positive; - , negative; $-/+,<50 \%$ positive.
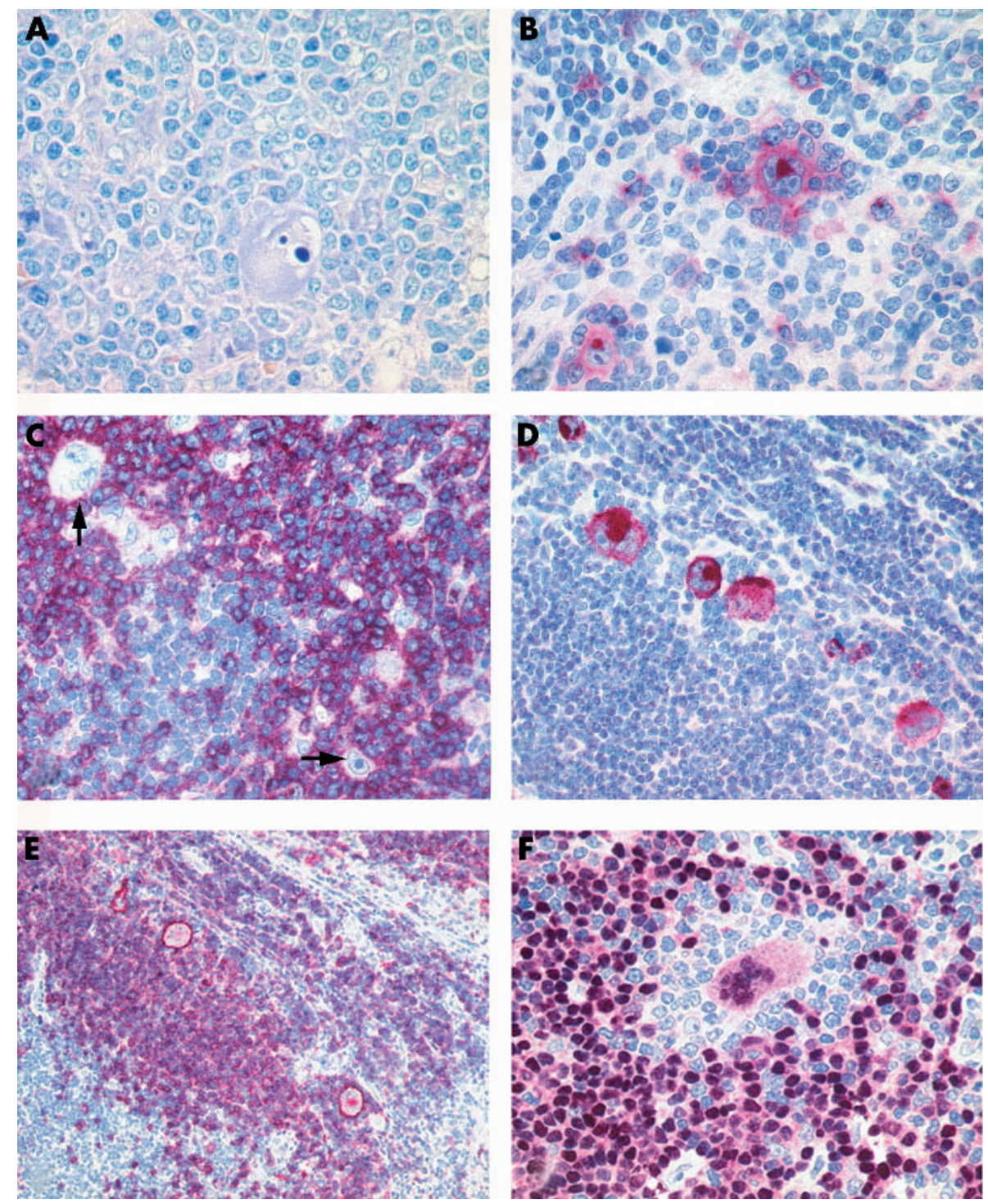

Figure 2 (A) Giemsa staining: single Reed-Sternberg cell detectable within a medium sized cell population. (B) Immunostaining for CD30 (alkaline phosphatase-anti-alkaline phosphatase (APAAP); Hodgkin and Reed-Sternberg (HRS) cells and a small part of the medium sized population clearly express CD30. (C) Immunostaining for CD3 (APAAP)); most of the medium sized cells are CD3 positive, whereas the HRS cells (arrows) are CD3 negative. (D) Immunostaining for Epstein-Barr virus encoded latent membrane protein 1 (EBV-LMP-1) (APAAP); the HRS cells are positive for the EBV-LMP-1. (E) Immunostaining for CD2O (APAAP); HRS and some small lymphocytes express CD20. (F) Immunostaining for BSAP (APAAP); HRS and some small lymphocytes are B cell specific activator protein (BSAP) positive. 


\section{Take home messages}

- We describe a composite lymphoma within a single cervical lymph node, composed of a cutaneous $T$ cell lymphoma and a classic Hodgkin lymphoma of $B$ cell type-a very rare finding indeed

- The true nature of this composite lymphoma was verified by immunohistochemical staining using a wide panel of antibodies, including those to T and B cells

thus suggesting $\mathrm{CHL}$ as an additional diagnosis to the CTCL component.

The presence of CHL in addition to CTCL raised the question of whether the two lymphomas were derived from the same cell of origin, or represented two different neoplastic cell clones. Occurrence of cHL in patients with CTCL, especially with mycosis fungoides, has been reported several times in the literature. In most of these cases a common clonal origin of both lymphomas could be demonstrated, ${ }^{2}{ }^{10}$ whereas only few cases showed a distinct clonal origin. ${ }^{711}{ }^{12}$ However, the simultaneous occurrence of two different clones within the same tissue seems to be a highly rare event. ${ }^{73}$

To elucidate any relation between CHL and CTCL in our patient, we investigated those features known to distinguish between cHL of the $\mathrm{B}$ cell type and the $\mathrm{T}$ cell type, respectively. TCR-PCR analysis of the skin and lymph node showed that the same clonal T cell population was present, identifying the neoplastic $\mathrm{T}$ cells in the lymph node as an infiltration of the known CTCL. To clarify the relation between the CHL and CTCL components, extensive immunohistological staining was performed (table 1); molecular analysis of antigen receptor rearrangement in single HRS cells could not be undertaken because of the absence of frozen tissue samples. Single cell analysis of paraffin wax embedded tissue was not performed because of extensive DNA degradation, as demonstrated by DNA quality control PCR (data not shown).

"To clarify the relation between the classic Hodgkin lymphoma and cutaneous $\mathrm{T}$ cell lymphoma components, extensive immunohistological staining was performed"

The HRS cells were partly positive for CD20 (fig lE) and the Epstein-Barr virus (EBV) encoded latent membrane protein I (fig ID), and expressed the B cell specific activator protein (BSAP) (fig lF). ${ }^{14}$ Furthermore, expression of the immunoglobulin transcription factor OCT2 was found only in a proportion of the HRS cells, whereas the OCT2 coactivator BOB.1/OBF.1 was not detectable. This finding was in complete agreement with the diagnosis of cHL and rules out an expansion of CD30 positive reactive B cell blasts. In contrast, there was no evidence of expression of $\mathrm{T}$ cell related molecules, including perforin and TIA-l. In particular, the absence of perforin is a strong indicator of the presence of a B cell-type cHL, as has been convincingly demonstrated in two independent studies. ${ }^{15}{ }^{16}$ In addition, most studies-with only one exception ${ }^{17}$-agree that the expression of BSAP strongly argues for B cell derived HRS cells. Furthermore, EBV was detected exclusively in our patient's HRS cells but not in the neoplastic T cells in the lymph node. Because EBV has not been found in T cell-type cHLs to date, this further supports the B cell nature of our HRS cells and, in addition, identifies the neoplastic $\mathrm{T}$ cells as a cell population distinct from the HRS cells. ${ }^{13}$

Based on the described expression profile, it seems highly likely that the CHL and CTCL tumour cells in the single cervical lymph node are unrelated to one another. Therefore, we conclude that the case presented here represents a true composite lymphoma, composed of B cell-type cHL and CTCL (fig 1, scenario III).

Although one could make many highly interesting speculations, this unusual coexistence of a B cell-type cHL and CTCL in a single lymph node probably reflects the coincidental development of $\mathrm{cHL}$ in a patient with an existing CTCL.

\section{Authors' affiliations}

M Steinhoff, C Assaf, R Treudler, C C Geilen, C E Orfanos, Department of Dermatology, University Medical Center Benjamin Franklin, The Free University of Berlin, 14195 Berlin, Germany

M Hummel, I Anagnostopoulos, H Stein, Institute of Pathology, University Medical Center Benjamin Franklin, The Free University of Berlin

Correspondence to: Dr M Steinhoff, Department of Dermatology, University Medical Center Benjamin Franklin, The Free University of Berlin, Fabeckstrasse 60-62, 14195 Berlin, Germany;

matthias.steinhoff@medizin.fu-berlin.de

Accepted for publication 12 September 2003

\section{REFERENCES}

1 Custer RP. Proceedings of the Second National Cancer Conference. New York: American Cancer Society, 1954;1:554-7.

2 Davis TH, Morton CC, Miller-Cassman R, et al. Hodgkin's disease lymphomatoid papulosis, and cutaneous T-cell lymphoma derived from a common T-cell clone. N Engl J Med 1992;326:1 115-20.

3 Marafioti T, Hummel M, Anagnostopoulos I, et al. Classical Hodgkin's disease and follicular lymphoma originating from the same germinal center B cell. J Clin Oncol 1999:17:3804-9.

4 Assaf C, Hummel M, Dippel E, et al. Common clonal T-cell origin in a patient with T-prolymphocytic leukaemia and associated cutaneous T-cell lymphomas. Br J Haematol 2003; 129:488-91.

5 van den Tweel JG, Lukes RJ, Taylor CR. Pathophysiology of lymphocyte transformation. A study of so-called composite lymphomas. Am J Clin Pathol 1979;71:509-20.

6 Kuppers R, Sousa AB, Baur AS, et al. Common germinal-center B-cell origin of the malignant cells in two composite lymphomas, involving classical Hodgkin's disease and either follicular lymphoma or B-CLL. Mol Med 2001;7:285-92.

7 Bee CS, Blaise YP, Dunphy CH. Composite lymphoma of Hodgkin lymphoma and mycosis fungoides: previously undescribed in the same extracutaneous site. Leuk Lymphoma 2001;42:543-9.

8 Dippel E, Assaf C, Hummel M, et al. Clonal T-cell receptor gamma-chain gene rearrangement by PCR-based GeneScan analysis in advanced cutaneous Tcell lymphoma: a critical evaluation. J Pathol 1999;188:146-54.

9 Steinhoff M, Hummel M, Anagnostopoulos I, et al. Single-cell analysis of $\mathrm{CD} 30+$ cells in lymphomatoid papulosis demonstrates a common clonal T-cell origin. Blood 2002;100:578-84.

10 Kadin ME, Drews R, Samel A, et al. Hodgkin's lymphoma of T-cell type: clonal association with a CD30+ cutaneous lymphoma. Hum Pathol 2001;32:1269-72.

11 Kremer M, Sandherr M, Geist B, et al. Epstein-Barr virus-negative Hodgkin's lymphoma after mycosis fungoides: molecular evidence for distinct clonal origin. Mod Pathol 2001;14:91-7.

12 Wlodarska I, Delabie J, De Wolf-Peeters C, et al. T-cell lymphoma developing in Hodgkin's disease: evidence for two clones. J Pathol 1993; 170:239-48.

13 Niedobitek G, Baumann I, Brabletz T, et al. Hodgkin's disease and peripheral T-cell lymphoma: composite lymphoma with evidence of Epstein-Barr virus infection. J Pathol 2000;191:394-9.

14 Foss HD, Reusch R, Demel G, et al. Frequent expression of the B-cell-specific activator protein in Reed-Sternberg cells of classical Hodgkin's disease provides further evidence for its B-cell origin. Blood 1999:94:3108-13.

15 Seitz V, Hummel M, Marafioti T, et al. Detection of clonal T-cell receptor gamma-chain gene rearrangements in Reed-Sternberg cells of classic Hodgkin disease. Blood 2000;95:3020-4.

16 Muschen M, Rajewsky K, Brauninger A, et al. Rare occurrence of classical Hodgkin's disease as a T cell lymphoma. J Exp Med 2000;191:387-94.

17 Willenbrock K, Ichinohasama R, Kadin ME, et al. T-cell variant of classical Hodgkin's lymphoma with nodal and cutaneous manifestations demonstrated by single-cell polymerase chain reaction. Lab Invest 2002;82:1103-9. 